\title{
The power of natural phenolic compounds: caffeic acid is able to enhance the retinoid-induced differentiation of tumor cells
}

\author{
Renata Veselska ${ }^{1,2^{*}}$, Petr Chlapek ${ }^{1}$, Miroslava Krzyzankova', Silvia Chovanova ${ }^{1,3}$, Jakub Neradil ${ }^{1,3}$, Karel Zitterbart $^{1}$, \\ Jaroslav Sterba ${ }^{1,2}$
}

From Metabolism, Diet and Disease 2014: Cancer and metabolism

Washington DC, USA. 28-30 May 2014

\section{Background}

The induced differentiation of tumor cells represents a very important strategy in modern antineoplastic therapy. Retinoids are the most frequently used group of cell differentiation inducers; however, their toxicity and intrinsic or acquired resistance to retinoids substantially limit their use in clinical protocols. Therefore, special attention has been paid to the combined treatment of cancer cells with retinoids and other compounds that may modulate (enhance or prolong) their antineoplastic effects. For example, combinations of retinoids and bile acids or inhibitors of the lipoxygenases and cyclooxygenases were reported as effective. Our research was focused on the caffeic acid (CA), a widely distributed plant phenolic compound, which is an inhibitor of 5-lipoxygenase.

\section{Materials and methods}

Eight cell lines derived from different types of pediatric solid tumors (neuroblastomas, medulloblastomas, osteosarcomas, and rhabdomyosarcomas) were chosen for this study. All-trans retinoic acid (ATRA) in concentration ranging from 0.05 microM to 10 microM was used as an inducer of cell differentiation. ATRA was applied alone or in combination with caffeic acid (CA) at concentrations of 13 and 52 microM; these concentrations of CA corresponded to the plasma levels obtained by its dietary uptake. Changes in cell morphology, proliferation activity, expression of differentiation markers and other cancerrelated genes were evaluated in treated cell populations.

\section{Results}

Although the cell lines showed various sensitivity to the ATRA treatment, the concentrations of CA used in this study were capable to enhance these antineoplastic effects of ATRA, especially in terms of cell differentiation.

\section{Conclusions}

Our results clearly showed that CA, which belongs to the natural phenolic compounds and is present in honey, apple juice, grapes and some other fruits and vegetables, may potentiate the cell differentiation of tumor cells induced by retinoids. These findings were confirmed using gene expression analysis that showed an increasing expression of genes involved in the process of the induced differentiation.

\section{Acknowledgements}

This study was supported by grant IGA NR9341-3/2007 by the European Regional Development Fund, as well as by the State Budget of the Czech Republic - project RECAMO CZ.1.05/2.1.00/03.0101, the project CEB CZ.1.07/ 2.3.00/20.0183 and the project PASSEB OP VK CZ.1.07/2.4.00/31.0155. We are grateful to Mrs. Johana Maresova for her technical assistance.

\section{Authors' details}

'Laboratory of Tumor Biology, Department of Experimental Biology, School of Science, Masaryk University, Kotlarska 2, 61137 Brno, Czech Republic. ${ }^{2}$ Department of Pediatric Oncology, University Hospital Brno and School of Medicine, Masaryk University, Cernopolni 9, 61300 Brno, Czech Republic. ${ }^{3}$ Masaryk Memorial Cancer Institute, Zluty kopec 7, 65653 Brno, Czech Republic.

Published: 28 May 2014
'Laboratory of Tumor Biology, Department of Experimental Biology, School of Science, Masaryk University, Kotlarska 2, 61137 Brno, Czech Republic Full list of author information is available at the end of the article
doi:10.1186/2049-3002-2-S1-P81

Cite this article as: Veselska et al:: The power of natural phenolic compounds: caffeic acid is able to enhance the retinoid-induced differentiation of tumor cells. Cancer \& Metabolism 2014 2(Suppl 1):P81. 